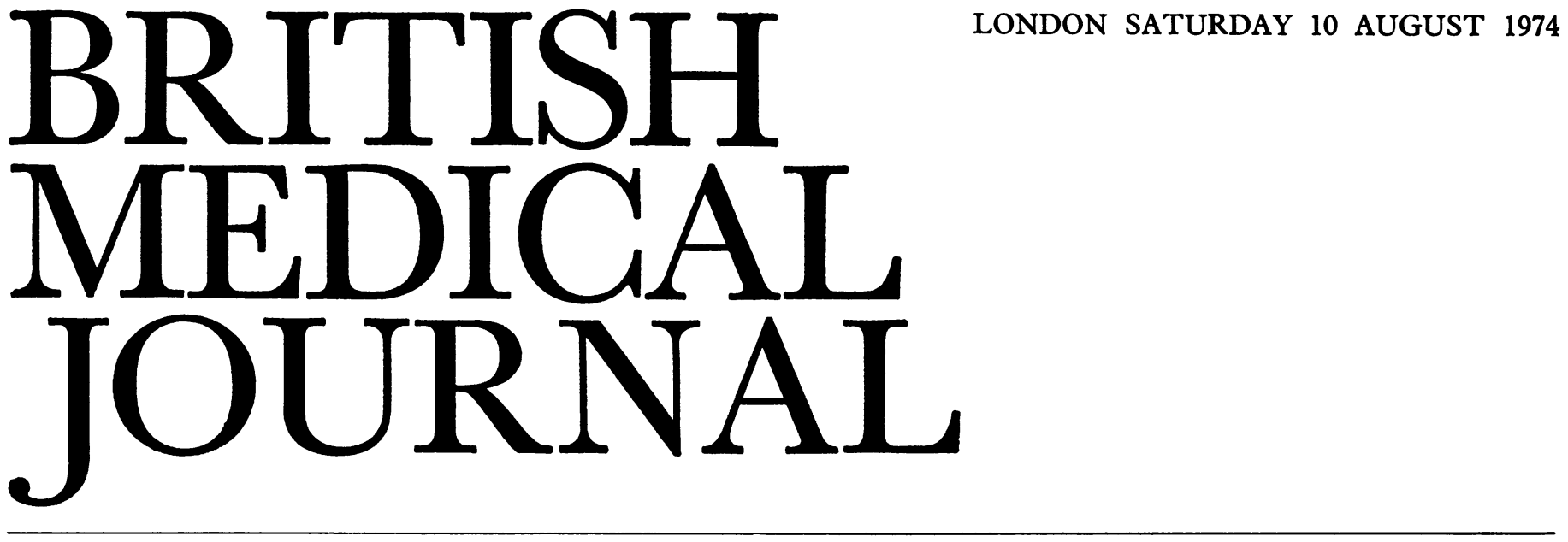

\title{
Drop-outs' Diarrhoea
}

Gastrointestinal disturbances often afflict the British when they venture across the Channel; nowadays "tummy upsets" are accepted as almost inevitable by many of the tourists who flock to the Mediterranean each year. The illness may be no more than a variant of the so-called travellers' diarrhoea ${ }^{1}$ which affects many visitors to underdeveloped countries with hot climates within a few weeks of arrival. This syndrome lurks under a variety of names-reminding us of the garrison towns of a former empire and delighting generations of medical students: Aden gut, Basra belly, Delhi belly, Gyppy tummy, and Hong Kong dog. It is also frequent in Central America, where it has been called turista, Aztec twostep, and Montezuma's revenge. Though travellers' diarrhoea is most common in areas where standards of sanitation and hygiene are poor it is thought to have a world-wide distribution and has even been reported ${ }^{2}$ in visitors to the U.S.A. The value of prophylaxis is still controversial, since there have been few good therapeutic trials; sulphonamides and neomycin may sometimes be effective, but the widely advertised iodochlorhydroxyquinoline (Entero-vioform) seems of little benefit. ${ }^{34}$

Until recently, it has been fashionable to attribute travellers' diarrhoea to the change in food or even to chilled drinks or cool draughts from fans. ${ }^{5}$ Traditionally, diarrhoea caused by amoebiasis, giardiasis, and helminth infestations are excluded from the syndrome-for Giardia lamblia may produce an acute attack of diarrhoea in travellers ${ }^{6}{ }^{7}$ which may then develop into chronic diarrhoea or a malabsorption syndrome. ${ }^{8}$ Standard bacteriological culture of the stools in travellers' diarrhoea suggests that salmonellae and shigellae account for only 5\% of the cases. A study of newly-arrived British soldiers in Aden showed that 19 out of 35 cases of diarrhoea harboured an undescribed serotype of Escherichia coli during the acute phase, whereas this type was never isolated from healthy controls. ${ }^{9}$ One year later, a technician working with the same serotype developed diarrhoea, and the organism was recovered from his stools. It was next shown to produce an enterotoxin which interferes with water and electrolyte transport in the small intestine, thus causing diarrhoea..$^{10}$ Finally, the same serotype produced gastrointestinal infections in volunteers. This work has not yet been confirmed by other field studies, and the cause of the diarrhoea in the remaining cases was not identified. It is tempting to blame an enterovirus infection for some cases, but no virus has yet been isolated, ${ }^{11} 12$ though the application of new techniques may prove fruitful. ${ }^{13} 14$ Similarly, a subtle alteration of the resident bowel microflora cannot yet be ruled out.
Now another variety of travellers' diarrhoea is described at p. 380 by Dr. A. M. Tomkins and his colleagues. The victims are the new breed of world travellers, hippies who live close to the people as they journey overland to Nepal in search of themselves ${ }^{15}$ (or perhaps marihuana). The illness begins with an acute attack of diarrhoea, vomiting, and sometimes fever at some point on the road to Kathmandu. However, the diarrhoea persists after the initial episode and is accompanied by steatorrhoea, abdominal distension, colic, and loss of weight. Absorption of fat, xylose, and vitamin $B_{12}$ is impaired; jejunal biopsy shows structural changes in the mucosa. The syndrome therefore begins as a form of travellers' diarrhoea and then develops into a form of tropical sprue without anaemia. It is important for clinicians in Britain to recognize this condition; sigmoidoscopy with routine microscopy and culture of the stools is not enough-it must be accompanied by absorption tests and jejunal biopsy or the diagnosis will be delayed. Furthermore, symptomatic treatment with codeine phosphate or diphenoxylate hydrochloride is inappropriate; oral tetracycline is needed and must be given for four weeks, since brief courses resulted in temporary improvement followed by relapse. Conversely, failure to respond to a four-week course of tetracycline should lead to revision of the diagnosis. The patients must also be followed up in order to diagnose and treat a late recurrence, another feature shared with tropical sprue.

Since the cause of the diarrhoea is not known prophylaxis is difficult. Nevertheless, intending "overlanders" should heed the general advice of Carey-Smith writing from Kathmandu. ${ }^{15} \mathrm{He}$ emphasized the importance of sufficient finance, an adequate and balanced diet, medical insurance, and protection against infectious diseases especially infectious hepatitis.

\footnotetext{
1 British Medical fournal, 1964, 2, 2.

Dandoy, S., California Medicine, 1966, 104, 458.

3 Kean, B. H., Annals of Internal Medicine, 1963, 59, 605.

Turner, A. C., British Medical fournal, 1967, 4, 653.

Kershaw, G. R., British Medical fournal, 1947, 1, 717.

Babb, R. R., Peck, O. C., and Vescia, F. G., fournal of the American Medical Association, 1971, 217, 1359.

Walzer, P. D., Wolfe, M. S., Schultz, M. G., fournal of Infectious Diseases, $1971,124,235$.

8 Peterson, H., Scandinavian Fournal of Gastroenterology, 1972, 7, 14.

9 Rowe, B., Taylor, J., Bettelheim, K. A., Lancet, 1970, 1, 1.

10 Formol, S. B., et al., Annals of the New York Academy of Sciences, 1971, 176, 190.

11 Rosenbluth, M. A., Schaffner, W., and Kean, B. H., American fournal of Tropical Medicine, 1963, 12, 329.

12 Bell, E. J., and Grist, N. R., British Medical fournal, 1967, 2, 741.

12 Bell, E. J., and Grist, N. R., British Medical

14 Bishop, R. F., et al., Lancet, 1973, 2, 1281.

15 Carey-Smith, K. A., New Zealand Medical fournal, 1974, 79, 696.
} 